\title{
PROSEDUR PEMBUATAN GIGI TIRUAN JEMBATAN IMMEDIATE 543 DENGAN OVATE PONTIC SEBAGAI RESTORASI SEMENTARA
}

\author{
Aris Setiawan ${ }^{1)}$, Suryani Catur $S^{2)}$, Triwindiari $S^{2)}$ \\ 1) Alumni Prodi DIII Teknik Gigi Poltekkes Tanjungkarang \\ ${ }^{2)}$ Dosen Prodi DIII Teknik Gigi Poltekkes Tanjungkarang
}

\begin{abstract}
Procedure of Making Artificial Dental Bridges 543 with Immediate Ovate Pontic as A Temporary Restoration. Bridge is protesa with tooth supporting as permanent in its position. By waiting the finishing of bridge making in laboratory. Second tooth which has been prepared need immediate restoration. This cases based on cases which is gotten in RSGM Central Lab Trisakti University, Jakarta 2015. Job instruction which is gotten is imitation tooth making bridge 543 as immediate restoration pra tooth cutting 4 with job model which is prepared. The methode is used is laboratorium procedure with heat curring acrylic. Protesa result can be good received and after one week there is no complain from dentist. Imitation tooth bridge immediate 543 with ovate pontic as immediate restoration help patient in solving of losing tooth between time.
\end{abstract}

Keywords: Bridge, Ovate Pontic, and Immediate Restoration.

\begin{abstract}
Abstrak: Prosedur Pembuatan Gigi Tiruan Jembatan Immediate 543 dengan Ovate Pontic sebagai Restorasi Sementara. Jembatan (bridge) adalah protesa dengan dukungan gigi yang disemen secara permanen pada posisinya. Selama menunggu penyelesaian pembuatan bridge di laboratorium, gigi sandaran yang telah dipersiapkan memerlukan restorasi sementara. Laporan kasus ini berdasarkan kasus yang diperoleh di Central Lab RSGM Universitas Trisakti, Jakarta tahun 2015. Instruksi kerja yang diperoleh adalah pembuatan gigi tiruan jembatan 543 pebagai restorasi sementara (immediate) pra- pencabutan gigi 4 dengan model kerja telah di preparasi. Metode yang dilakukan adalah prosedur laboratorium dengan bahan heat curring acrylic. Hasil protesa dapat diterima baik, dan setelah satu minggu tidak ada complain dari dokter gigi. Gigi tiruan jembatan immediate 543 dengan ovate pontic sebagai restorasi sementara membantu pasien dalam menanggulangi kehilangan gigi antar waktu.
\end{abstract}

Kata Kunci : Jembatan, Ovate Pontic, dan Restorasi Sementara.

Perkembangan dunia kedokteran gigi memungkinkan penyelesaian masalah kesehatan gigi dan mulut lebih komprehensif dan lebih memuaskan. Masalah yang sering timbul adalah kehilangan gigi yang memerlukan gigi pengganti untuk mengembalikan fungsi gigi: mastikasi, fonetik, estetik, dan kesehatan jaringan. Kehilangan gigi dapat disebabkan oleh proses pencabutan, trauma, anomaly (tidak erupsi).

Pembutan gigi tiruan dapat berupa gigi tiruan cekat atau lepasan. Pada umumnya protesa cekat berupa crown atau bridge lebih disenangi oleh penderita dibandingkan geligi tiruan lepasan. Prosedur pembuatan bridge memerlukan waktu beberapa hari sehingga pasien mengalami masa kehilangan gigi (ompong), untuk mengatasi hal tersebut dibuatkan bridge sementara . Menurut Prajitno (1994) Jembatan sementara yang baik ialah yang memenuhi persyaratan sebagai perlindungan pulpa, stabilitas kedudukan, fungsi oklusal, mudah dibersihkan, kekuatan dan retensi, dan estetika (Rosenstiel,dkk, 2001).

Prosedur pembuatan bridge sementara di laboratorium dapat menggunakan bahan self curring acrylic atau heat curring acrylic. Bahan heat curring memiliki beberapa kelebiahan dalam hal kekuatan, warna, porositas minimal.

Komponen bridge terdiri dari retainer, connector, pontik. Pontik didesain sedemikian rupa untuk mendapat keuntungan maksimal. Macam-macam desain pontik: saddle (ridge lap), modified ridge lap, hygienic, conical, dan ovate (Shillingburg, 1997).

Segmen atau bagian ovate pontic yang kontak dengan jaringan dibentuk tumpul membulat dan ke dalam cekungan dari soket. Hal ini memudahkan pontik dibersihkan dengan benang gigi atau dental floss. Kecekungan 
bridge dapat terisi dengan penempatan servikal ovate pontic dengan perluasan seperempat bagian pontik (sedalam 2-3 $\mathrm{mm}$ ) ke dalam soket segera setelah pencabutan gigi (Banerjee $\mathrm{R}$, dkk, 2010, Dylina TJ, 1999).

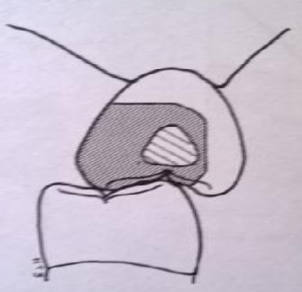

Gambar 1. Ovate Pontic (Shillingburg, 1997)

Menurut Prajitno (1994) Jembatan sementara yang baik ialah yang memenuhi persyaratan sebagai perlindungan pulpa, stabilitas kedudukan, fungsi oklusal, mudah dibersihkan, kekuatan dan retensi, dan estetika. Desain ovate pontic pada restorasi sementara gigi tiruan jembatan posterior immediate dapat mengembalikan fungsi mastikasi, sebagai pelindung soket pasca pencabutan, menjaga higienis, stabilitas kedudukan, dan meretraksi gingiva untuk menghasilkan bentuk bridge sesuai desain ovate pontic.

\section{METODE PENELITIAN}

Sebuah Model dari dokter gigi yang diterima Central Lab RSGM Usakti tahun 2015 dengan surat perintah kerja (SPK) pembuatan restorasi sementara pra-pencabutan gigi premolar satu rahang atas kanan(imme-diate bridge) satu hari selesai (one visit). Tata laksana kasus diawali dengan mempersiapkan model untuk pekerjaan laboratorium.

Model kerja dari dokter gigi dibersihkan dari nodul-nodul, dan gigi yang direncanakan untuk dicabut diberi tanda.

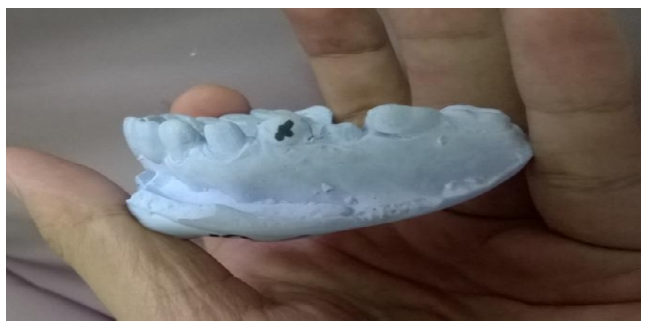

Gambar 2. Model Kerja

Tahap selanjutnya ialah menentukan batas mesial dan batas distal pada model, lalu membuang gigi 4 dengan bantuan gergaji secara perlahan sedikit demi sedikit, dan meradir dengan bantuan scapel hingga batas bagian servical. Sisi bukal diradir $5 \mathrm{~mm}$ dan sisi palatal $3 \mathrm{~mm}$, lalu dilanjutkan pembentukan soket berbentuk cekungan membulat sedalam $2 \mathrm{~mm}$.

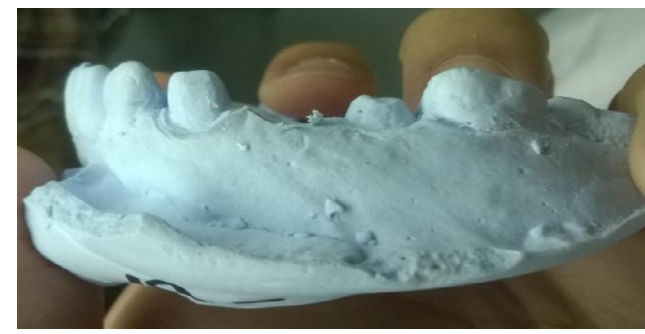

Gambar. 3 Tahap pembuatan socket

Pola malam dibentuk dengan menggunakan lecron pada bagian servikal, mesial dan distal hingga bentuknya menyerupai gigi aslinya. Akhiran servikal pontik diberi bentuk ovate pontic dengan cara bagian servical pontik masuk ke dalam soket gigi yang dibentuk sedalam $\pm 2 \mathrm{~mm}$.

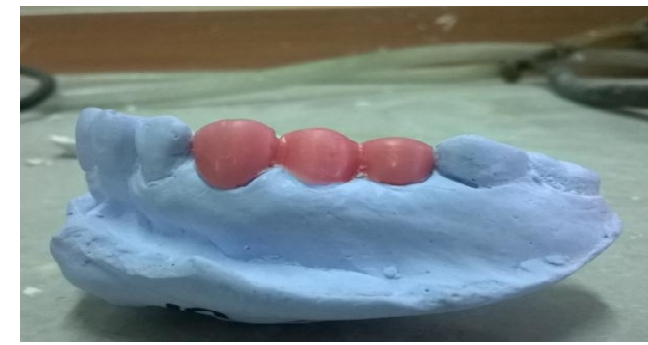

Gambar 4. Pola malam pada model kerja

Selanjutnya model malam ditanam (flasking) dalam kuvet (Gambar 5a). Setelah mengeras dilanjutkan dengan proses boiling out.

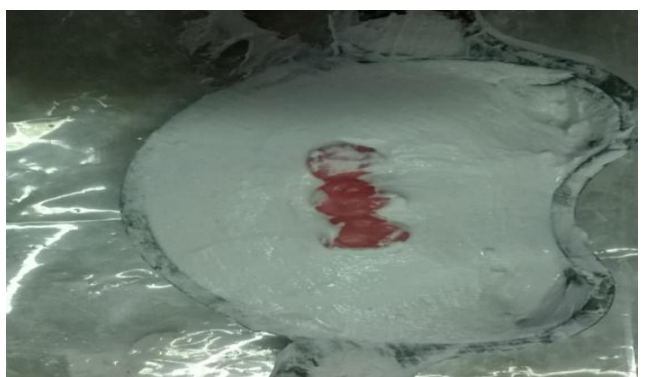

Gambar 5a. Flasking model

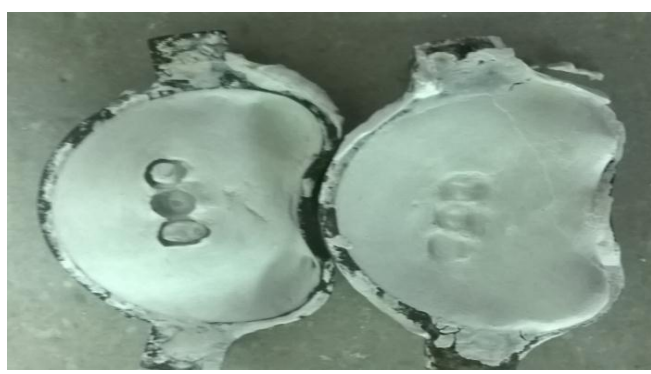

Gambar 5b. Hasil boilling out

Pada prosedur boiling out ini seluruh sisa malam (wax) dibersihkan, tepi-tepi bahan tanam 
yang tajam dirapihkan (Gambar 5b). Seluruh permukaan model (mould space) diulas dengan larutan CMS untuk menghindari perlengketan acrylic dengan bahan tanam sehingga protesa dapat dikeluarkan dengan mudah.

Tahapan berikutnya adalah packing acrylic (Gambar 6) dengan menggunkan metode dry pack, dengan cara meneteskan liquit dan dilanjutkan penaburan powder sampai seluruh mould space terisi penuh. Selanjutnya permukaan luar dilapisi selopan kemudian tutup dengan kuvet atas, dan dilanjutkan dengan trial press perlahan-lahan. Kuvet dibuka kembali untuk membuang kelebihan akrilik yang keluar dari batas mould space menggunakan lecron. Kemudian dilakukan press kedua untuk memastikan tidak ada gelembung udara yang terjebak (porus).

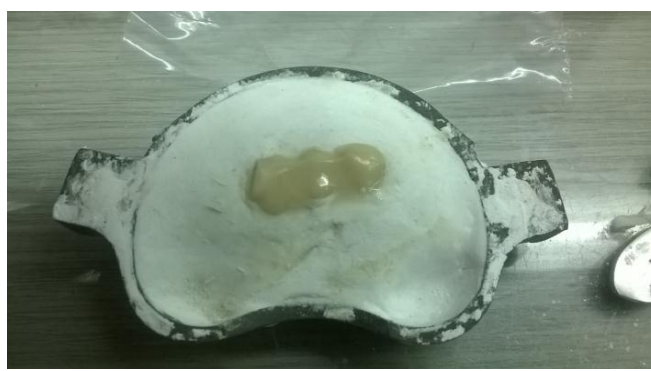

Gambar 6. Packing acrylic

Tahap selanjutnya curring, yaitu memasak akrilik dalam air mendidih selama 1,5 jam. Tahap ini merupakan tahap polimerisasi akrilik untuk mendapatkan protesa dengan sifatsifat fisik yang baik.

Prosedur dilanjutkan mengeluarkan bridge dari kuvet, Fitting Margin (Gambar 7), Finishing, dan polishing. Kelebihan akrilik yang ada pada gigi dihilangkan terutama dibagian incisal, mesial, distal, buccal/labial, dan servikal gigi menggunakan bur fissure, serta diperhatikan kontak dengan gigi tetangga.

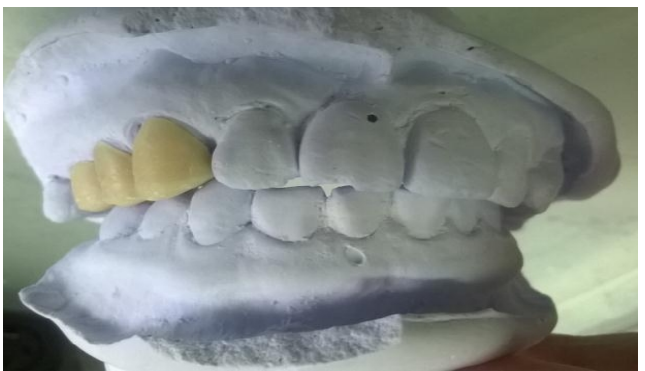

Gambar 7. Fitting margin

Semua permukaan protesa diratakan dengan amplas sampai tidak ada lagi bagian yang tajam, dan bentuk anatomi gigi tidak berubah sampai menyerupai gigi aslinya.

Selanjutnya, dilakukan pemolesan menggunakan feltcon dan sikat hitam diulasi pumice secukupnya. Lalu, pergunakan white brush diulasi $\mathrm{CaCO}_{3}$ secara berulang. Proses pemolesan dilakukan secara berhati-hati sampai permukaan licin, dan mengkilap (Gambar 8).

Protesa yang telah selesai dibuat langsung dikirim ke dokter gigi untuk segera dipasang di mulut pasien. Kontrol dilakukan setelah satu minggu protesa dipasang, dan dilaporkan tidak ada keluhan pada pasien (tidak ada komplain dari dokter gigi).

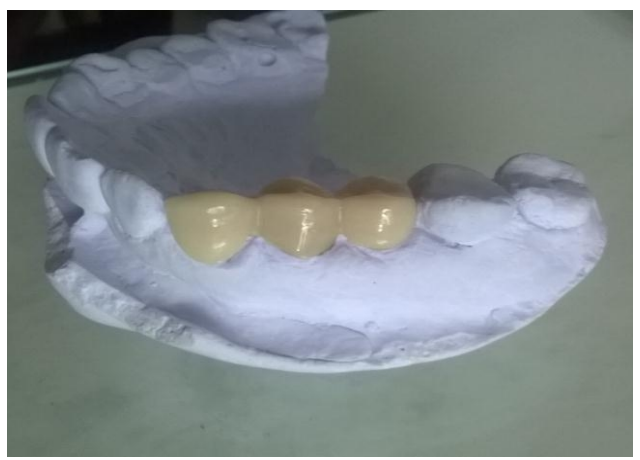

Gambar 8. Bridge telah selesai

\section{PEMBAHASAN}

Kehilangan gigi pada sebagian besar orang menyebabkan gangguan estetik yang bermakna, sehingga memerlukan tindakan segera. Gigi tiruan cekat (crown and bridge) merupakan salah satu solusinya.

Pembuatan immediate bridge sebagai protesa sementara merupakan salah satu cara untuk mengatasi kehilangan gigi antar waktu menunggu bridge permanen selesai dibuat. Immediate bridge ini selain memberikan keuntungan secara estetik, juga membantu proses penyembuhan luka pasca pencabutan gigi. Ovate pontic dipertimbangkan sebagai pengganti pontik tipe saddle untuk mendapatkan estetika yang baik dan kemudahan untuk dibersihkan. Pontik ini diindikasikan untuk penatalaksanaan ovate pontic untuk gigi yang belum dicabut maupun sudah dicabut. Fungsi pembuatan ovate pontic ini sendiri mengembalikan estetika gigi asli dengan gigi tiruan sehingga Nampak alami, nyaman saat digunakan, menghalangi benda asing masuk kedalam soket serta desain ini sangat higienis. Pada pembuatan gigi tiruan jembatan posterior, fungsi ovate pontic lebih dominan pada fungsi biologis dan mekanis dibandingkan estetis.

Teknik pembuatan jembatan sementara dengan ovate pontic ini membentuk servikal pontik masuk ke dalam cekungan lokasi bekas pencabutan $\pm 2 \mathrm{~mm}$ di bawah gusi untuk 
mendapatkan kesan alami dan secara signifikan mencegah penumpukan sisa makanan di daerah tersebut. Pada bagian mesio-distal dan bukolingual dibentuk sedemikian rupa sehingga nampak ramping dan ujung apikal masuk ke dalam cekungan bridge bekas pencabutan gigi. Hal ini memudahkan pontik dibersihkan dengan benang gigi (dental floss), sehingga higienitas terpelihara dan dapat membantu proses penyembuhan soket gigi.

Karakteristik jembatan (bridge) sementara yang baik meliputi: perlindungan terhadap pulpa gigi penyangga, stabil pada posisinya, membantu fungsi mastikasi, mudah dibersihkan sehingga tidak menyebabkan peradangan terhadap jaringan sekitar,ketepatan akhiran servikal (fit), memiliki kekuatan dan retensi yang baik, serta memiliki estetika yang dapat diterima baik oleh pasien. Jembatan immediate sebagai restorasi

\section{DAFTAR PUSTAKA}

Banerjee R, Banerjee S, Radke U. 2010. Ovate Pontic Design: An Aesthetic Solution To Anterior Missing Tooth. Journal Of Clinical And Diagnostic Research, VSPM Dental College and Research Centre. India: $2999 \mathrm{hlm}$.

Dylina, T.J. 1999. Contour Determination for Ovate Pontic. Journal of The Prosthetic Dental, Volume 82, $142 \mathrm{hlm}$.

Prajitno, H.R., Yuwono, Lilian (Ed.). 1994. Ilmu Geligi Tiruan Jembatan: sementara dengan desain ovate pontik memberikan hasil yang baik dan memuaskan. Karena desain ini menghasilkan soket gigi pasca pencabutan yang ideal sebagai persiapan jembatan permanen dengan desain pontik yang sama.

\section{SIMPULAN}

Pembuatan gigi tiruan jembatan immediate $\begin{array}{lllll}5 & 4 & 3\end{array}$ dengan ovate pontic sebagai restorasi sementara membantu pasien dalam menanggulangi kehilangan gigi antar waktu. Pekerjaan ini memerlukan kerjasama yang baik antara dokter gigi dan tekniker guna mendapatkan hasil yang optimal. Komunikasi yang baik merupakan kunci kesuksesan rencana perawatan.
Pengetahuan Dasar dan Rancangan Pembuatan. Jakarta : Penerbit Buku Kedokteran EGC,Cetakan Kedua, 168 hlm.

Rosenstiel., Land., Fujimoto. 2001. Contempory Fixed Prostodontics. China: Mosby Elsevier, $709 \mathrm{hlm}$.

Shillingburg, H.T., at all. 1997. Fundamentals of Fixed Prostodontics, Canada: Quintessence Publishing Co, Inc, 490 hlm. 